This paper reports a study into the influence of the main design parameters of power transmission lines on energy losses associated with the corona discharge; a method has been devised to reduce them. The structure of the split-phase wire, the distance to the ground, and between the centers of the phases of the line are determined at the design stage. Based on these structural parameters, the value of specific energy losses associated with the corona discharge is calculated. Studying the impact exerted on the amount of losses by each structural parameter makes it possible at the design stage to determine the structure of a power transmission line (PTL) with low energy losses. Reducing energy loss when transporting it along the line is one of the most important issues in the strategy for the development of the energy industry at the stage of the "green transition". It has been established that most structural parameters have a weak effect on the values of corona loss$e s$, and, if there is a significant impact, the implementation of such solutions leads to a large increase in the cost of constructing an overhead transmission line. Based on the analysis of the results of calculations of corona losses in power transmission lines, it was determined that the corona losses in the middle phase of the transmission line are much greater than in the extreme phases. That has made it possible to devise a method for reducing power corona losses associated with the alignment of the capacities of all phases of PTL. This effect is achieved by calculating, based on the developed method, the splitting step of the middle phase of PTL. The calculation of the splitting step is based on the preliminary determination of the capacity of the extreme phases and the substitution of calculated values in the resulting expression for the splitting step. The possibility of such a reduction in corona losses should significantly increase the energy efficiency of AC power transmission lines, especially in areas with large periods of different weather that provoke the occurrence of a corona discharge on the wires of their phases. This circumstance causes an increase in this type of pozer loss

Keywords: power transmission line, structural parameters of power transmission line, power corona losses, line phase capacitance
UDC 621.315 .1

DOI: $10.15587 / 1729-4061.2022 .253384$

\title{
DEVISING A METHOD FOR REDUCING ACTIVE POWER CORONA LOSSES BASED ON CHANGING THE STRUCTURAL PARAMETERS OF A POWER TRANSMISSION LINE
}

Sergi Shevchenko

Doctor of Technical Sciences, Professor, Head of Department*

Eniola Olubakinde

PhD Student*

Dmytro Danylchenko

Corresponding author

$\mathrm{PhD}$, Associate Professor*

E-mail: dmytro.danylchenko@khpi.edu.ua

Ihor Nazarenko

Doctor of Technical Sciences, Professor

Department of Electrified Agricultural Technologies

Dmytro Motornyi Tavria State Agrotechnological University

B. Khmelnytsky ave., 18, Melitopol, Ukraine, 72312

Natalia Savchenko

$\mathrm{PhD}$, Associate Professor

Department of Electrical Engineering

Donetsk National Technical University

Shybankova sq., 2, Pokrovsk, Ukraine, 85300

Larysa Shylkova

Doctor of Philosophy, Associate Professor

Department of Electrical Machines**

*Department of Electric Power Transmission**

**National Technical University "Kharkiv Polytechnic Institute"

Kyrpychova str., 2, Kharkiv, Ukraine, 61002

\section{Introduction}

One of the priority tasks of modern energy generation is to reduce losses in the transmission and distribution of electricity. The volume of losses of electricity affects the economic performance of the power system and leads to additional fuel use. Reducing energy losses during transmission can reduce harmful emissions of combustion products of organic fuel to the atmosphere [1].

Transmission of electricity is associated with noticeable losses. The difference between electricity received in the network and supplied to consumers, which is determined by the data of the system of accounting for its receipt and useful supply, is called actual or reporting losses of electricity. Their enlarged structure consists of four main parts:

1) technical losses of energy caused by physical processes occurring in electrical equipment obtained by means of calculation;

2) electricity consumption for own substation needs, necessary for the operation of technological equipment in the electrical network and life support of service personnel registered by metering devices; 
3) losses of electricity arising during its measurement from instrumental errors obtained by calculation based on data on metrological characteristics;

4) commercial losses caused by theft of electricity and failure to pay for it.

Losses of electrical energy depend on the operating conditions of electrical network equipment and on the design features of such equipment. One of the most important elements of the electricity transmission system is the overhead power transmission lines (PTL). Losses of active energy on power lines, due to physical processes, make a significant contribution to the total losses in the networks of the power system. These losses can be divided into two parts. The first part is the loss of heating wires, which depend on the current that flows through the wires of power lines. The second part is the losses associated with the corona discharge on the wires, which, in turn, are associated with the voltage on the PTL wire [2]. These losses have different physical essences and can be considered separately from each other.

Losses associated with the corona discharge on power lines are called corona losses. Physically similar losses are losses of active energy associated with the flow of corona current in the ionized air zone near the wire. The process of coronal discharge and its development in time are well studied. The exact determination of the amount of corona losses is a rather complex process associated with the presence of means of fixing the parameters of the electrical network mode [3]. At present, the value of corona losses is normalized in the form of specific fixed values for a certain phase design. However, such normalization was appropriate when fixing all structural parameters of the phase, with the exception of the number of wires and their diameter. The rules for electrical installations (PUE) of the 2017 edition make it possible to change all the design parameters of phase wires without exception. The ability to change the structural parameters of power transmission lines leads to a change in electric fields arising on the wires of split phases. The change in charge in the phase causes a change in the intensity of the electric field on the components of the split. Specific energy losses associated with the corona discharge depend on the ratio of the tension at the beginning of the corona and the tension on the wire of the line determined by its electric field. Changing this ratio affects the amount of energy loss. An effective means of combating the corona is the splitting of the phases of the line.

At present, corona losses amount to $20-25 \%$ of the total losses of the power system [2]. However, with a network load of $50-60 \%$, corona losses can be from 40 to $50 \%$. This fact allows us to assert that the analysis of the impact of the structural parameters of the transmission line on the amount of electricity corona losses is an urgent problem that could help define the methods of reducing such losses.

\section{Literature review and problem statement}

Most authors investigate the impact on losses from the corona exerted by the structural parameters of power transmission lines, not taking into consideration the possibility of changing them at the design stage. In work [2], an attempt was made to reduce losses by covering the wire with polymer coating. It should be noted that this technique of reducing losses can be quite costly. The authors of [4] offer to measure corona losses using the telemechanic system. Such a system will not make it possible to make predictive estimates of corona losses, which are performed in the power system. In [5], a system for monitoring energy losses to the corona for dispatch services is proposed. Thus, the system will make it possible to quickly make decisions on voltage adjustment. However, it does not take into consideration the ability to reduce corona losses at the design stage.

The authors of [6] propose to change the losses from the corona by one or another technique of voltage regulation in the network. However, the implementation of such adjustments requires the use of specific devices. Such regulation will be limited by the system's ability to withstand voltage changes without disrupting the operating mode.

Work [7] reports a study into the effect of the corona on the values of overvoltage on power lines. During the study, it was necessary to investigate the effect of the structural parameters of the phase of power lines on overvoltage and the presence of the corona. The authors of work [8] examined the dynamics of losses from the corona discharge on power lines $750 \mathrm{kV}$ in time. The results obtained indicate an increase in such losses during the operation of power lines. In [8], no means or method of reducing these losses is proposed.

The intensity of corona losses depends on weather conditions, for example, in rainy weather, corona losses increase by an order of magnitude. The authors of [9] paid great attention to such changes. It should be noted that the accuracy of determining the impact of weather factors on corona losses is quite low, due to the not accurate idea of the time of presence of a particular type of weather in the area where the overhead line track passes. At the design stage, engineers have only approximate data on the time of continuation of weather types that affect the calculations of both electrical and economic parameters of the overhead line.

Analysis of the impact of the design parameters of the overhead lines on losses from the corona will make it possible to determine how each of these parameters affects the corona losses on the line. The study of literary sources reveals the need to investigate such influences. To this end, you need to perform a number of calculations of corona losses for overhead lines of various structures.

\section{The aim and objectives of the study}

The purpose of this study is to devise a method for reducing energy losses associated with the corona discharge on power lines with various design parameters. This will make it possible at the PTL design stage to reduce energy corona losses, by improving the structure of the split phase of PTLs.

To accomplish the aim, the following tasks have been set:

- to calculate power corona losses with a change in the design parameters of PTLs;

- to determine the possibility of changing the structure of the split phase of PTL as a factor influencing the reduction of power corona losses.

\section{The study materials and methods}

\subsection{Methodology for determining losses associated} with the corona discharge on a power transmission line

To analyze the values of electrical energy losses caused by the corona discharge on the wires of power lines, the recommended procedure for determining such losses was used [10]. This procedure includes calculating the intensity 
of the electric field on the surface of the wires and comparing it with the intensity of the beginning of the corona under different types of atmospheric conditions. This approach makes it possible to calculate specific corona losses in various structural implementations of phases and line supports. In addition, this procedure makes it possible to derive the value of losses of electrical energy on corona in any atmospheric phenomena that affect the physical processes of the coronal discharge on the wires of PTLs.

\section{2. The materials and equipment used in the calcu-} lations

To analyze the dependence of corona losses on the design of power lines, the main brands of wires used for the construction of ultra-high voltage power lines were selected. In addition, typical schemes of power lines supports are used for calculations, which determine the possible booms of sagging wires in the span. As an example, calculations were performed for PTLs with a voltage of $330 \mathrm{kV}$. The choice of such a rated voltage was due to existing representations and regulatory documents on corona losses on power lines.

\section{The results of studying corona losses in power transmission lines of various structures}

\section{1. Calculations of power corona losses}

One of the most important factors influencing the performance of energy systems is the loss of energy accompanying its transmission and distribution. At present, Ukraine's electricity networks have quite high loss rates, which are included in the tariff for electricity. The amount of loss of electrical energy determines the efficiency of PTL. Modern ultrahigh voltage lines have quite a high efficiency, which is $95-98 \%$. However, the capacity of $330 \mathrm{kV}$ PTL is approximately $300 \mathrm{MW}$. Therefore, reducing losses for such a line by $1 \%$ could lead to a power saving of $3 \mathrm{MW}$. Given the length of such PTLs, the savings are significant.

The main factor influencing corona losses is, of course, the wires of PTLs and their design features. For PTL with a rated voltage of $330 \mathrm{kV}$, so-called split wires are used. The structural execution of such a wire is shown in Fig. 1.

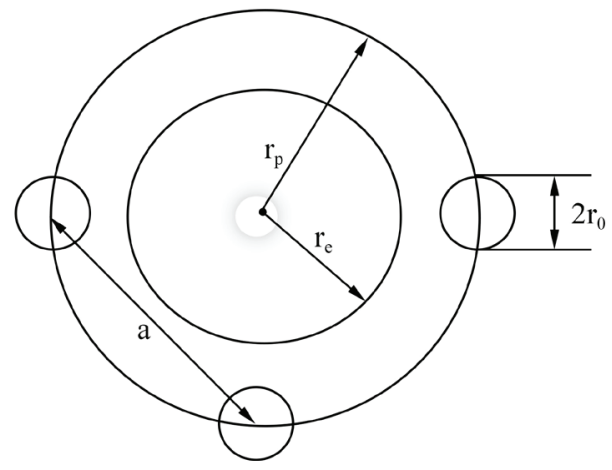

Fig. 1. The design of the split phase of a power transmission line: $a-$ wire splitting step; $r_{p}-$ splitting radius;

$r_{e}-$ equivalent radius of the wire; $r_{0}-$ radius of the component split phase

Splitting radius

$$
r_{p}=\frac{a}{2 \sin (\pi / n)},
$$

equivalent radius

$$
r_{e}=\sqrt[n]{r_{p}^{n-1} \cdot n \cdot r_{0}}
$$

where $n$ is the number of wires in the phase, $r_{0}$ is the radius of the component of the split phase.

The three main design parameters are the equivalent height $\left(H_{e}\right)$ of the suspension of the wire and the height of the wire suspension on the support $\left(H_{n}\right)$ and the distance between the centers of adjacent phases $(D)$.

$$
H_{e}=H_{n}-\frac{2}{3} f
$$

where $H_{e}$ is the equivalent height of the suspension of the wire; $f$ - the boom of sagging wire;

$H_{n}$ - the height of the suspension of the wire on the support.

The use of such wire structures is associated with the prevention of corona discharge and a decrease in power losses in the transmission of energy through power lines. The parameters of the wire design are selected according to regulatory documents.

The splitting step and the number of wires that make up the phase determine its structure. The remaining parameters can be calculated taking into consideration the brand of the wire. However, the PTL design as a whole is also affected by the distance between phases and the distance from the wire to the ground. Therefore, our paper analyzes the influence of the above-mentioned structural parameters of power lines on energy corona losses.

For the analysis, a procedure was used that was recommended for calculating corona losses on the overhead transmission lines with the correction of the determination of phase capacitance. The phase capacitance was calculated using the software developed at the Department "Transmission of Electric Energy", the National Technical University "Kharkiv Polytechnic Institute". Underlying this program is the principle of calculating electrostatic fields based on potential coefficients. The specified procedure of calculating the intensity of the electric field on the wires of power lines makes it possible to take into consideration the duration of a particular atmospheric phenomenon and calculate the specific corona losses.

After calculating the capacitance, the intensity of the electric field at each phase of PTL was determined from the expressions given below.

The average intensity in the appropriate phase

$$
E_{a v i}=0.0147 \frac{C_{i} U}{n r_{0}},
$$

where $C_{i}$ is the working capacitance of the corresponding phase, $U$ is the rated voltage of PTL.

The intensity of the onset of corona

$$
E_{0}=20.1 \cdot \text { air } \cdot\left(1+\frac{0.613}{\left(\text { air } \cdot r_{0}\right)^{0.4}}\right) \text {, }
$$

where air is the relative density of air

$$
\text { air }=0.00289 \frac{p}{273.16+t},
$$

where $p=101325 \mathrm{~Pa}=760 \mathrm{~mm} \mathrm{Hg}, t$ is temperature, degree Celsius, ${ }^{\circ} \mathrm{C}$. 
Equivalent intensity on the wire

$$
E_{e i}=E_{a v i}\left(1+\frac{\alpha \cdot \beta^{2} \cdot r_{0}^{2} \cdot E_{a v i}}{4 \cdot a^{2} \cdot E_{0}}\right)
$$

where $\beta=2 \times(n-1) \sin (\pi / n), \alpha$ is the coefficient taking into consideration the dependence of corona losses on weather type.

Calculations are carried out for four types of weather (good weather, snow, rain, frost). To this end, you need to determine the coefficient, which depends on the number of wires in the phase $k_{w i}$. The expression for it takes the form from [11]:

$$
k_{w i}=x-y \frac{E_{e i}}{E_{0}} .
$$

The $k_{w i}$ coefficient is calculated for the specified types of weather for each phase separately.

The calculation of the ratio of the equivalent intensity and the intensity of the onset of corona, taking into consideration the values of the coefficients, is carried out according to the expression:

$$
\operatorname{otn}_{i}=\frac{E_{e i} \cdot k_{a} k_{w i}}{E_{0}} .
$$

This ratio is calculated for all types of weather under consideration in each phase.

Depending on the splitting step, the influence of the neighboring components of the split phase on the electric field that exists on each of the changes. The coefficient of such influence $k_{a}$ is derived using the plot shown in Fig. 2 [12].

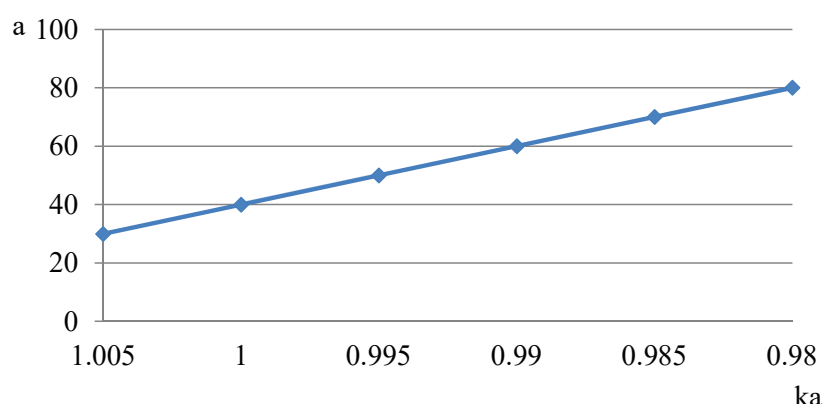

Fig. 2. Dependence of the refining coefficient on the step of phase splitting of a power transmission line

Depending on the calculated value of the ratio, corona losses for all types of weather and phases of power lines are determined.

$$
\Delta P_{k i}=F n_{i} r_{0 i}^{2} E_{e i} / 10^{3}[\mathrm{~kW} / \mathrm{km}],
$$

where $F=f\left(o t n_{i}\right)$ is the dependence of generalized corona losses on the ratio of equivalent intensity and the intensity of the onset of corona with refining coefficients.

Corona losses for a given phase design are calculated from the expression

$$
\Delta P_{k 3 f}=\sum_{i=1}^{3} \Delta P_{k i}[\mathrm{~kW} / \mathrm{km}]
$$

Power corona losses, taking into consideration the time of existence of a particular type of weather, are calculated from the following expression

$$
\Delta P_{c w i}=\Delta P_{k 3 f} t_{w i i} / 8760[\mathrm{~kW} / \mathrm{km}] .
$$

For each type of weather, we have a different time of its action $t_{1}, t_{2}, t_{3}, t_{4}$, respectively.

Power corona losses for the line as a whole during the year is calculated from the formula

$$
\Delta P_{c}=\sum_{1}^{i} \Delta P_{c w i}[\mathrm{~kW} / \mathrm{km}]
$$

To analyze the impact exerted on power losses by the structural parameters of PTL, the design of power lines with a rated voltage of $330 \mathrm{kV}$ was used. Such PTLs have at least two wires in the phase but, according to the Rules for electrical installations [13], the designer has the opportunity to use another number of components.

In the beginning, the dependence of corona losses on the distance of the phase wire to the surface of the earth, which is called the size to the ground, was calculated. The possibility of changing the height of the wire above the ground is due to the area of the route of the line in different types of terrain [8]. The results of calculations according to the above methodology for PTLs with a rated voltage of $330 \mathrm{kV}$ at two components in the phase of intersection of 400 , dimensions to the ground $7 \mathrm{~m}$, sagging boom $12 \mathrm{~m}$, the distance between the centers of phases $8 \mathrm{~m}$, and splitting step $40 \mathrm{~cm}$, are shown in Fig. 3 .

The next series of calculations, for the same design of PTL, involved determining the dependence of specific power corona losses on the sagging boom. Our results are shown in Fig. 4.

The next step in the calculations was to determine a change in the corona losses when changing the distance between the adjacent phases for the same design of PTL. Our results are shown in Fig. 5.

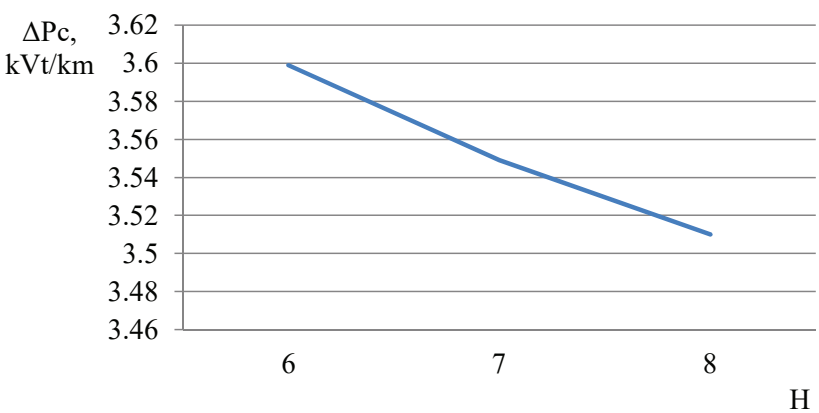

Fig. 3. Dependence of specific corona losses on the size to the ground $(H)$ of a power transmission line with the same sagging boom

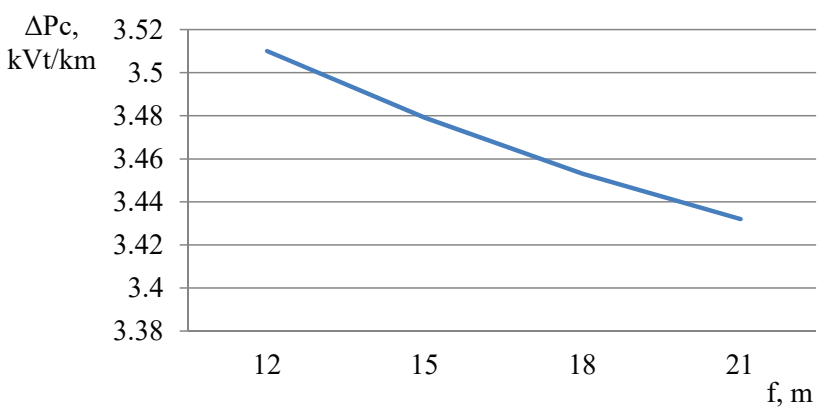

Fig. 4. Dependence of specific corona losses on the boom of sagging of the transmission line with an unchanged dimension to the ground $(H)$ 


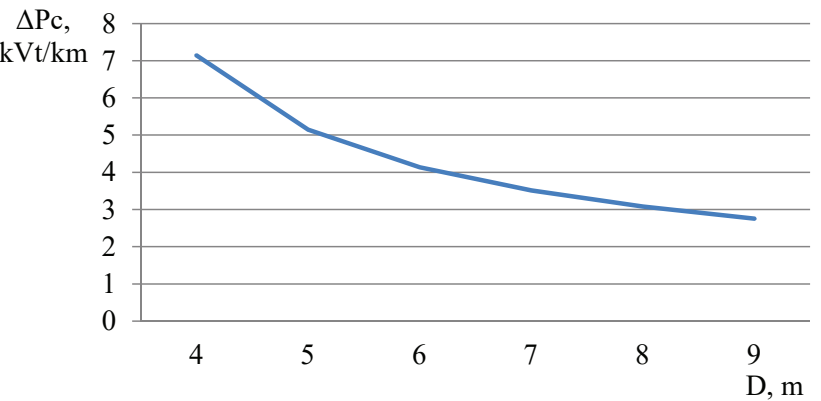

Fig. 5. Dependence of specific corona losses on the distance between the centers of phases with an unchanging boom of sagging of the transmission line and dimensions to the ground

During our study, the influence of the intersection of the components of the split phase on the specific power loss corona was analyzed. However, it is quite difficult to compare and analyze the results obtained. The main factor in the inability to compare the results obtained is the difference in phase intersections that are formed when using different sections of wires. For example, if the PTL phase is composed of two wires, then when using a wire $2 \times \mathrm{AS} 400$, the phase intersection is $800 \mathrm{~mm}$, and with wires $2 \times \mathrm{AS} 300$ and $2 \times \mathrm{AS} 240-600$ and 480 , respectively.

For qualitative analysis of the impact of the intersection of the components of the split phase on corona losses, three structures of the phase of power lines of $330 \mathrm{kV}$ were selected, which have close total sections of phases $(2 \times$ AS 400 , $3 \times \operatorname{AS} 300$, and $4 \times \operatorname{AS} 240$ ). The results of our calculations according to the suggested procedure of the loss values in these phase designs are shown in Fig. 6 for each section separately.

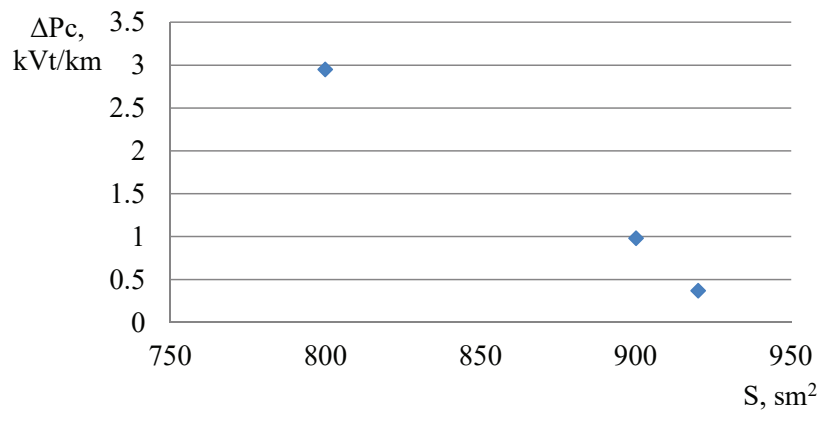

Fig. 6. Dependence of specific corona losses on the total intersection of the phase of the transmission line for different structures of the split phase $(2 \times$ AS $400,3 \times$ AS 300 , and $4 \times$ AS 240)

The next structural parameter investigated in this work is the phase wire splitting step. The recommended splitting step is $40 \mathrm{~cm}$. This recommendation is based on the classic understanding of the corona discharge. It indicates that at a distance between wires of $30-40 \mathrm{~cm}$, the intensity of the electric field on the surface of the wire is the lowest. The magnitude of the intensity predetermines the volume of corona losses. The results of calculations according to the suggested methodology are shown in Fig. 7.

The final parameter of the phase design investigated in the process of our work was the number of wires that make up the split phase of PTL. It should be noted that an increase in the number of wires in the phase will lead to a significant increase in the intersection. Therefore, it is possible to decide on the use of additional wires at the design stage only based on the results of technical and economic comparison of phase design options. It is also necessary to provide for the need to compensate for additional reactive power. The results of calculations at the same initial parameters according to the specified methodology are shown in Fig. 8.

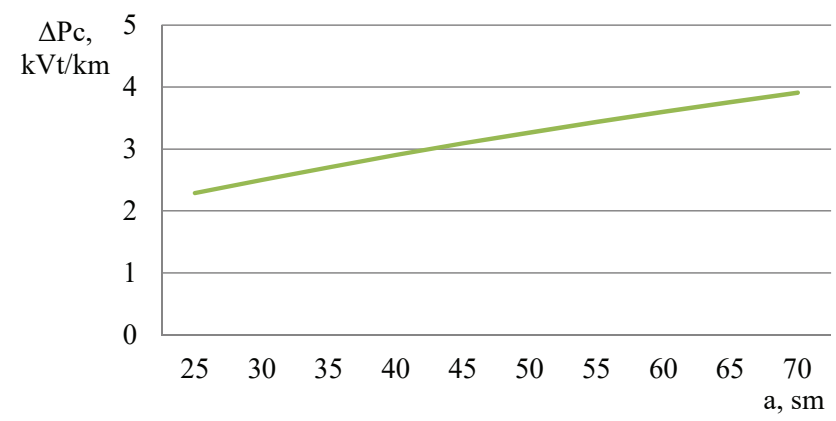

Fig. 7. Dependence of specific corona losses on the step of phase splitting

$\Delta \mathrm{Pc}, \quad 3.5$

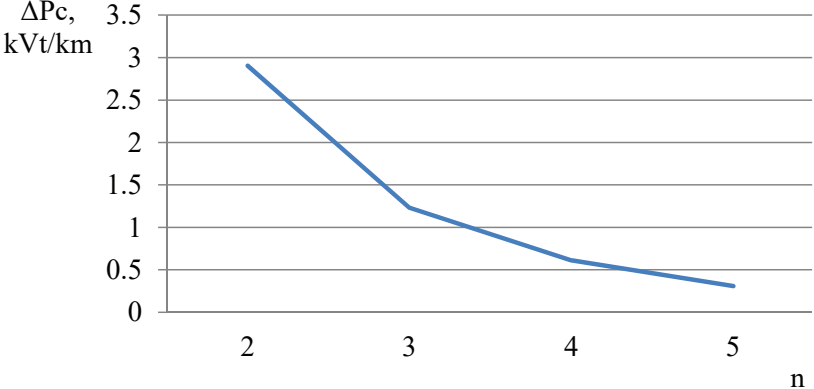

Fig. 8. Dependence of specific corona losses on the number of wires in the split phase of a power transmission line

Our estimation studies into the impact of structural parameters on losses associated with the corona discharge reflect their dependence on the PTL structure. The main assumption in the calculations was the position of all PTL phases horizontally above the ground.

5. 2. Determining the possibility of changing the design of the PTL split phase as a factor influencing the reduction of power corona losses

In the process of calculations, it turned out that the PTL middle phase makes the greatest contribution to the addition of corona losses for different types of weather. This becomes apparent from the analysis of phase capacitance changes. With the horizontal arrangement of wires on the support, our calculations show that the middle phase has the largest capacitance, and, accordingly, the charge. This fact indicates the most difficult, in terms of the intensity of the electric field, operating conditions of the middle phase. To illustrate this fact, the estimated values of power corona losses for power lines with a rated voltage of $330 \mathrm{kV}$ were taken, which were derived using the above procedure for the above PTL parameters. Data in Table 1 indicate that the middle phase produces approximately $45 \%$ of the total power corona losses. This result has made it possible to assume that the reduction of working capacitance of the middle phase of PTL by reducing the splitting step would significantly affect the amount of power losses.

To analyze this assumption, a well-known expression was used for the capacitance of the split wire [14]. 


$$
C=\frac{2 \pi \varepsilon_{0} \varepsilon}{\ln \left[\frac{\sqrt[3]{2} D_{0}}{r_{e} \sqrt[3]{\left[1+\left(D_{0} / H_{e}\right)^{2}\right] \sqrt{1+\left(D / H_{e}\right)^{2}}}}\right]}
$$

where $\varepsilon_{0}$ is the dielectric permeability of the vacuum; $\varepsilon$ - relative dielectric permeability of the medium; $D$ - the distance between the centers of phases, $r_{0}$ - the radius of the component of the split phase, $H_{e}$ - the equivalent height of the suspension of the wire.

To simplify the expression for the phase capacitance of the line, the following designation was introduced

$$
T=\sqrt[3]{\left[1+\left(D_{0} / H_{e}\right)^{2}\right] \sqrt{1+\left(D / H_{e}\right)^{2}}}
$$

The expression for determining the equivalent radius through the phase capacitance is as follows:

$$
r_{e}=\frac{\sqrt[3]{2} D_{0} e^{C}}{e^{2 \pi \varepsilon_{0}} T}
$$

Based on expression (2), for an equivalent radius, an estimation formula was derived for the splitting radius of the phase of PTL

$$
r_{p}=\frac{\sqrt[3]{2} \sqrt[n-1]{n r_{0}} D_{0} e^{C}}{e^{2 \pi \varepsilon_{0}} T}
$$

Taking into consideration expression (1) to determine the splitting radius and expression (15), a formula was derived to calculate the splitting step of the PTL phase

$$
a=\frac{2 \sqrt[3]{2} \sin (\pi / n) \sqrt[n-1]{n r_{0}} D_{0} e^{C}}{e \sqrt[2 \pi \varepsilon_{0}]{\sqrt[3]{\left[1+\left(D_{0} / H_{e}\right)^{2}\right] \sqrt{1+\left(D / H_{e}\right)^{2}}}}}
$$

Thus, an expression was built to determine the splitting step of the air line phase, which will equalize the capacitance of the extreme phases with the middle phase, which will reduce corona losses in PTL. The results of the calculation for the phase $2 \times$ AS 400 structure are shown in Fig. 9 .

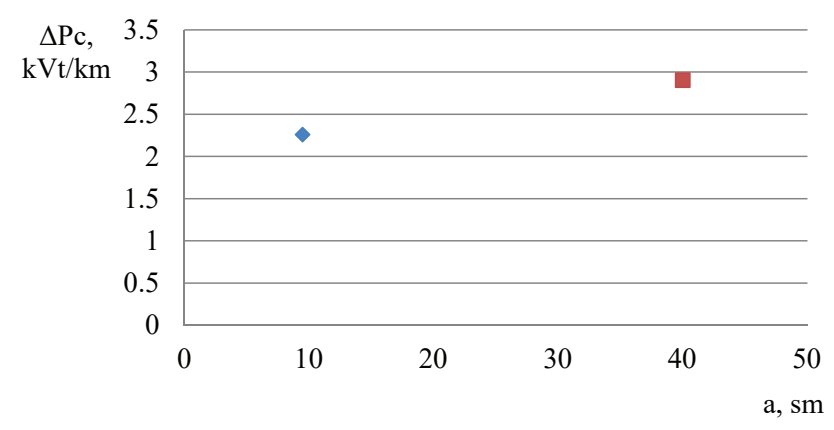

Fig. 9. Dependence of specific corona losses on the step of splitting the middle phase of the transmission line:

- corona losses at the splitting step of the middle phase $a=10 \mathrm{~cm}, \mathbf{a}-$ corona losses at the splitting step $a=40 \mathrm{~cm}$

Our calculations showed a significant dependence of energy corona losses on the radius of the middle phase of PTL.
Table 1

Results of calculating corona losses for different types of weather

\begin{tabular}{|c|c|c|c|c|}
\hline \multirow{2}{*}{ PTL phase } & \multicolumn{4}{|c|}{ Weather type } \\
\cline { 2 - 5 } & Good & Snow & Rain & White frost \\
\hline A, C & 0.267 & 0.934 & 3.922 & 9.429 \\
\hline B & 0.463 & 1.687 & 6.745 & 15.163 \\
\hline Summa & 0.997 & 3.554 & 14.589 & 34.022 \\
\hline
\end{tabular}

\section{Discussion of results of studying corona losses in the} power transmission lines

The results of the calculations, shown in Fig. 3, show that corona losses can be significantly reduced with an increased size of PTL. However, such a decrease requires rather large capital investments due to changes in the design of supports. In addition, the design practice is based on albums of typical solutions that have passed the verification of the relevant authorities. These albums are based on typical support structures produced industrially, making reducing or increasing the size to the ground almost impossible. Reducing power corona losses when changing the size by $2 \mathrm{~m}$ would be only about $2 \%$. As you can see in Fig. 4, increasing the sagging boom by 9 meters results in a decrease in power corona losses by about 3 percent. This makes such a technique ineffective because to increase the sagging boom, it is necessary to increase the load on the supports of power lines. Such an increase would result in the unreasonable use of metal in the design of PTL supports.

Our results indicate an increase in specific corona losses when the distance between the centers of the phases of power lines changes downwards (Fig. 5). This result is due to the increase in the charge of the wire of PTL when the phases converge, which leads to an increase in the intensity of the electric field on the wire, which determines the amount of corona losses.

The study reported here shows a significant dependence of specific corona losses on the structural implementation of the phase. Fig. 6 demonstrates that specific losses change significantly. For example, during the transition from the phase $2 \times \mathrm{AS} 400$ design to a structure containing $3 \times$ AS 300 , the losses decreased by about 2.8 times, but the total cross-section increased by $100 \mathrm{~mm}^{2}$, which equals its growth of about 12 percent. When the phase design changes to $4 \times \mathrm{AS} 240$, the total cross-section will increase by about 14 percent, and the power corona losses will decrease by 8 times. The obtained values of corona losses make it possible to assert that changing the design of the phase by increasing the number of components in it with a smaller single section is an effective method of combating power corona losses. However, it should be noted that the existing regulatory framework practically does not make it possible at the design stage to develop structural elements of power lines in such a way as to be able to make changes to the structure of the split phase by increasing the number of components. In addition, the issue of the choice of phase design has a technical and economic component, which is associated with an increase in the required number of compensating devices and with a change in the design of the projected PTL supports. 
Fig. 7 illustrates a fairly rapid reduction in power corona losses with an increase in the number of components of the split phase of PTL. However, the growth in the overall cross-section of such a phase is quite large, which causes the need to use more powerful supports and leads to an increase in the charging power of PTL, which requires additional means of compensation. Fig. 8 shows the dependence of power corona losses on the step of splitting the phase of the line. The results of our calculations indicate an increase in corona losses with an increase in the splitting step. This is due to an increase in phase capacities due to an increase in the splitting radius, which leads to an increase in the intensity of the electric field on the surface of the wires.

Our study into the effect of structural parameters of PTL on corona losses has shown a rather weak efficiency of their change to reduce these losses. The derived values of corona losses indicate that the change in one of the structural parameters of power lines does not lead to a decrease in corona losses. We can also say that any structural solution to reduce corona losses leads to an increase in the cost of construction of PTL.

Based on the study reported here, a method for reducing corona losses has been proposed, which involves leveling the capacitance of the phases of power lines by determining the value of the splitting step of the middle phase. It should be noted that this method could be used in the horizontal location of the phases of PTL. The method involves two stages. At the first stage, the calculation of capacitance for all 3 phases is carried out. At the second stage, the splitting step of the middle phase is calculated based on the estimated capacitance equal to the capacitance of the extreme phase in preliminary calculations. As you can see from Fig. 9, with a decrease in the splitting step of the middle phase to about $10 \mathrm{~cm}$ (determined by the above method of reducing corona losses of power lines), corona losses are reduced by $20 \%$.

Our calculations testify to the possibility of technical implementation of such a phase. To this end, you do not need to change the main structural elements of PTL, which are defined by typical albums for designing lines. In addition, it is not necessary to develop new support structures because the weight loads on them almost do not change.

It should be noted that the devised method can be used only during the design, construction, and reconstruction of power lines with a horizontal arrangement of phases. For other structural execution of PTL, it is necessary to determine specific tools for reducing corona losses. To determine the method of reducing energy corona losses for two-circuit supports, additional research is needed. The difficulty in determining such a method is the need to construct an additional mathematical apparatus for calculating corona losses for two-circuit PTL.

\section{Conclusions}

1. We have calculated specific power corona losses for PTL of $330 \mathrm{Kv}$ with different structural execution. A weak dependence of such losses on changes in the design parameters of power lines has been revealed. This dependence during the calculations ranged in about $2-3 \%$. This indicates the possibility of influencing corona losses by the structural parameters of PTL. However, there are significant restrictions in terms of the technical and economic feasibility of use.

2. Our calculation studies have made it possible to devise a method for reducing corona losses, which involves leveling the capacitance of PTL phases by determining the value of the splitting step of the middle phase. If the splitting step of the middle phase is reduced to about $10 \mathrm{~cm}$ (determined by the above method of reducing corona losses of PTL), corona losses are reduced by $20 \%$.

\section{Acknowledgments}

We express our gratitude to well-known specialists in the field of PTL designs Prof. G. Alexandrov, Prof. G. Pidporkin, V. Redkov, Y. Gerasimov, Assoc. Prof. Y Seleznev, and others for their significant contribution to the study of the impact of the structural features of overhead power transmission lines on the modes of their operation.

\section{References}

1. Breido, I., Kaverin, V., Voytkevich, S. (2018). Distribution of Power Losses on High-Voltage Supports. DAAAM Proceedings, 0329-0337. doi: https://doi.org/10.2507/29th.daaam.proceedings.047

2. Shevchenko, S., Koval, A., Danylchenko, D., Koval, V. (2020). Energy Crisis and Electricity Reform of Ukraine - First Results. 2020 IEEE KhPI Week on Advanced Technology (KhPIWeek). doi: https://doi.org/10.1109/khpiweek51551.2020.9250119

3. Diahovchenko, I., Mykhailyshyn, R., Danylchenko, D., Shevchenko, S. (2019). Rogowsky coil applications for power measurement under non-sinusoidal field conditions. Energetika, 65 (1). doi: https://doi.org/10.6001/energetika.v65i1.3972

4. Kuchanskyy, V., Zaitsev, I. O. (2020). Corona Discharge Power Losses Measurement Systems in Extra High Voltage Transmissions Lines. 2020 IEEE 7th International Conference on Energy Smart Systems (ESS). doi: https://doi.org/10.1109/ ess50319.2020.9160088

5. Blinov, I., Zaitsev, I. O., Kuchanskyy, V. V. (2020). Problems, Methods and Means of Monitoring Power Losses in Overhead Transmission Lines. Studies in Systems, Decision and Control, 123-136. doi: https://doi.org/10.1007/978-3-030-48583-2_8

6. Riba, J.-R., Larzelere, W., Rickmann, J. (2018). Voltage Correction Factors for Air-Insulated Transmission Lines Operating in HighAltitude Regions to Limit Corona Activity: A Review. Energies, 11 (7), 1908. doi: https://doi.org/10.3390/en11071908

7. Leman, J. T., Olsen, R. G. (2020). Bulk FDTD Simulation of Distributed Corona Effects and Overvoltage Profiles for HSIL Transmission Line Design. Energies, 13 (10), 2474. doi: https://doi.org/10.3390/en13102474 
8. Liu, Y., Chen, S., Huang, S. (2018). Evaluation of Corona Loss in $750 \mathrm{kV}$ Four-Circuit Transmission Lines on the Same Tower Considering Complex Meteorological Conditions. IEEE Access, 6, 67427-67433. doi: https://doi.org/10.1109/access.2018.2878763

9. Bousiou, E. I., Mikropoulos, P. N., Zagkanas, V. N. (2020). Corona inception field of typical overhead line conductors under variable atmospheric conditions. Electric Power Systems Research, 178, 106032. doi: https://doi.org/10.1016/j.epsr.2019.106032

10. Tamazov, A. (2016). Poteri na koronu v vysokovol'tnyh vozdushnyh liniyah elektroperedachi. Moscow: Sputnik+, 572.

11. Rukovodyaschie ukazaniya po uchetu poter na koronu i pomekh ot korony pri vybore provodov vozdushnyh liniy elektroperedachi peremennogo toka 330 - $750 \mathrm{kV}$ i postoyannogo toka 800-1500 kV (1975). Moscow: STSNTI ORGRES, 87.

12. Gul', V. I., Nizhevskiy, V. I., Homenko, I. V., Shevchenko, S. Yu., Chevychelov, V. A. (2009). Koordinatsiya izolyatsii i perenapryazheniya v elektricheskih vysokovol'tnyh setyah. Kharkiv, 270.

13. Pravyla ulashtuvannia elektroustanovok (2017). Kуiv, 617. Available at: https://art-energetyka.com.ua/Правила-улаштування-електроустановок.pdf

14. Aleksandrov, G. N. (1989). Ustanovki sverhvysokogo napryazheniya i ohrana okruzhayuschey sredy. Leningrad: Energoatomizdat. Available at: https://www.elec.ru/viewer?url=files/2019/11/26/aleksandrov-gn-ustanovki-sverhvysokogo-napryazheni.pdf 